\title{
Effect of a complex prebiotic preparation on the preservation, growth intensity and microflora in rabbits' intestine
}

\author{
V.P. Lyasota' ${ }^{1}$, T.I. Bakhur*1, M.V. Utechenko1, M.M. Fedorchenko' ${ }^{1}$, I.O. Rublenko', N.V. \\ Bukalova ${ }^{1}$, N.M. Bogatko ${ }^{1}$, A.A. Antipov' ${ }^{1}$, S.A. Tkachuk ${ }^{2}$, T.M. Prilipko ${ }^{3}$, \\ N.I. Sakhniuk ${ }^{1}$, A.F. Bogatko ${ }^{1}$ \\ ${ }^{1}$ Bila Tserkva National Agrarian University, Bila Tserkva, Kyiv region, Ukraine \\ ${ }^{2}$ Institute of Veterinary Medicine of the National Academy of Sciences of Ukraine, Kyiv, Ukraine \\ ${ }^{3}$ State Agrarian and Engineering University in Podilya, Kamianets-Podilskyi, Khmelnytskyi region, Ukraine \\ Corresponding author E-mail: fly 13@ukr.net
}

Received: 29.10.2020. Accepted 30.11.2020

\begin{abstract}
We presented the effect of prebiotic "Bio-active" on preservation, increase of the body weight, the microflora composition in the distal small intestine, histological examination of the intestinal wall and liver of rabbits gray giant breed 45 days aged. Prebiotic "Bioactive" contains products of metabolism of lactic acid bacteria Lactobacillus bulgaricus delbrueckii adsorbed on zeolite. Our results proved the safety of this prebiotic for the rabbits. Optimal scheme for oral administration of the prebiotic was $2.0 \mathrm{~g}$ per $1 \mathrm{~kg}$ of body weight for 30 days. Such a course provided $95 \%$ of animal preservation and increase in the weight gain of the experimental animals, an average of $43.1 \%$ compared with the non-treated rabbits. In scarifies of distal intestine in $20 \%$ of animals that received the prebiotic and in $100 \%$ of those who did not receive it, Bacteria of Proteus genus have been detected. After the course of prebiotic we registered an increased number of Enterobacteriaceae (4.5-6.0 × 108 CFU) and Bifidobacteria (8 $\times 107-108 \mathrm{CFU})$ in rabbits' intestines. We also mentioned the enhanced gram-positive/gram-negative ratio with a predominance of gram-positive (1:1.17 against 1:2.9 in control group). In case of prebiotic usage, the stimulation of goblet cells' development was determined in the small intestine walls. Almost $100 \%$ of rabbits, who did not receive the prebiotic, had dystrophic changes in hepatocytes (74.5 \% of the animals had fatty hepato-dystrophy and $25 \%$ had protein granular dystrophy). We registered that only $25 \%$ of the animals had fatty hepato-dystrophy and $15 \%$ had protein granular dystrophy among those, which received the preparation.

Keywords: prebiotic; microflora; rabbits; intestine; metabolism; resistance; productivity
\end{abstract}

\section{Introduction}

Violations of the qualitative and quantitative composition of normal intestinal microflora of farm animals are accompanied by various aetiology pathological conditions. Changes in microbiocenosis of the intestine, in turn, can cause a number of disorders of metabolic and immune status. This is evidenced by the close connection between the normal microflora of the body, its immune reactivity and the course of many biochemical processes (Blaser, 2016; Wiley et al., 2017).

Antibiotics and chemo-therapeutic drugs used in veterinary medicine for the treatment and prevention of gastrointestinal diseases of animals, cause the selection and circulation of pathogenic and opportunistic microorganisms with increased resistance to antibiotics. It also threatens the animal's organism with the appearance of dysbiosis. The result of these processes is a reduction in the effectiveness of the drugs' using, which poses a potential threat to the health of animals and humans (Beyene, 2016; Arrazuria et al., 2016).

In the last two decades, the practice of human and veterinary medicine, for the prevention and treatment of the gastrointestinal tract's disorders, are widely used microbial drugs - pro- and prebiotics. Unlike antibiotics, eubiotics do not cause addiction from the part of the opportunistic microflora, the products of their life do not accumulate in the organs and tissues of the animals' body and do not degrade the quality of products, and they are safe for the media (Phuoc and Jamikorn, 2016; Ford et al., 2018).

The mechanism of action of probiotics is aimed at suppressing the growth of pathogenic microorganisms, increasing the activity of the immune system and better assimilation of nutrients in the feed (Tsuboi et al., 2015; Rios et al., 2016).

Lactic acid bacteria - one of the most numerous groups of microorganisms of the gastrointestinal tract. They produce a large amount of lactic acid, promoting the development of other types of microorganisms such as Bofidobacteria, Propionibacteria, Butyiuvibrio, Roseburi, support fermentation and formation of organic acids. This reduces the pH in the large intestine, decreases the number of E. coli, Salmonella and other pathogenic microorganisms (Yang et al., 2015; Donaldson et al., 2016).

The purpose of the research was to establish the syngeneic effect of the bioactive prebiotic on the preservation, growth intensity and development of the normal microphlora of the intestines of rabbits, to histologically investigate the distal part of the small intestine and rabbit liver after the use of eubiotic.

\section{Methods}

Experimental studies were performed in accordance with the order of the State Department of Veterinary Medicine of the Ministry of Agrarian and Industrial Complex of Ukraine No. 7 of February 17, 1999 "On Strengthening the Control of the Quality and Safety of Veterinary Medicines and Feed Additives" and in accordance with the International Standard GLP (Good Laboratory Practice).

Composition of the studied prebiotic 
The object of the research was the influence of the biologically active preparation - pre-biotic "Bio-active", developed by Private Enterprise "BTU-Center", (Ladyzhin, Trostyanets district, Vinnitsa region, Ukraine). The preparation is a powdery substance of gray colour, which contains products of metabolism of lactic acid bacteria Lactobacillus bulgaricus delbrueckii adsorbed on zeolite. This zeolite belongs to a class of silicates of skeleton structure and is a natural medicinal product that causes cation exchange and adsorption processes.

Livelihood products of lactic acid bacteria, included in the studied preparation, when they enter the intestines of an animal, produce a complex of special enzymes: proteases, specific peptidase - proliodase, which hydrolyzes proteins with high content of proline and has unique ways of biosynthesis regulating.

"Bio-active" prebiotic also includes amino acids used to synthesize hormones, enzymes, and vitamins without intermediate updating of the "old" proteins of the body and is one of the most important factors in animal metabolism. lysine - $0.67 \mathrm{mg} / \%$; histidine $1.0 \mathrm{mg} / \%$; aspartic acid - $33.77 \mathrm{mg} / \%$; threonine - $3.36 \mathrm{mg} / \%$; serine $-14.81 \mathrm{mg} / \%$; glutamic acid - $10.51 \mathrm{mg} / \%$; glycine $10.59 \mathrm{mg} / \%$; alanine - $7.79 \mathrm{mg} / \%$; cystine $5.23 \mathrm{mg} / \%$; valine $-2.81 \mathrm{mg} / \%$; methionine - $0.3 \mathrm{mg} / \%$; isoleucine - $3.99 \mathrm{mg} / \%$; leucine $-0.37 \mathrm{mg} / \%$; tyrosine $-0.91 \mathrm{mg} / \%$; phenylalanine $-4.01 \mathrm{mg} / \%$.

The analysis of the results of biochemical studies of the prebiotic "Bio-active" showed that $1 \mathrm{~g}$ of the preparation contains vitamin $\mathrm{B} 1-0.13 \mu \mathrm{g} / \mathrm{g} ; \mathrm{B} 2-0.17 \mu \mathrm{g} / \mathrm{g} ; \mathrm{B} 12-0.0012 \mu \mathrm{g} / \mathrm{g} ;$ carotinoids - $3.0 \mu \mathrm{g} / \mathrm{g}$; vitamin A - $0.627 \mu \mathrm{g} / \mathrm{g}$ and vitamin $\mathrm{E}-$ $3.0 \mu \mathrm{g} / \mathrm{g}$. Extremely important is the presence of carotenoids and vitamins $A$ and $E$ as the most active antioxidants and coenzymes.

\section{Formation of experimental animal groups}

According to the principle of pair of analogues, five groups of rabbits (4 experimental and 1 control) of the gray giant breed were formed: 20 animals of the same age (45 days) and sex (males) in each. Rabbit was kept in identical conditions. The probiotic was fed for 30 days as a feed supplement at doses of $0.8,1.0,1.5,2.0 \mathrm{~g}$ per animal once a day, adding to the main ration (the optimum dose was selected).

\section{Microbiological techniques of intestinal mucosa study}

Samples of scarifies from the intestinal mucosa were taken from the distal intestine after slaughter of rabbits. Samples were tested in the Bila Tserkva Municipal Laboratory of Veterinary Medicine. Specific and quantitative composition of the microflora was determined by the following methods. Seeding of biological material was carried out in meat-peptone broth (MPB), in bacteriological cups with meat-peptone agar (MPA), and in blood agar. For seeding of one sample, 5 cups or tubes were used. The surface of the agar before seeding was dried up. Seeding was made using a sterile spatula in accordance with the Drigalsky method, applying 0.1 $\mathrm{cm}^{3}$ of biologic material suspension to a surface of an agar. After they were cultured in a thermostat at $37^{\circ} \mathrm{C}$ for 24 hrs (Zantow et al., 2018). For detection of coliform bacteria, cultures were performed on a selective media with lactose Endo, cultured at $37^{\circ} \mathrm{C}$ for 24 hours (Zhang et al., 2015).

To detect bacteria of Proteus genus, morphology and the presence of characteristic growth on nutrient media, the ability to hydrolyze urea and form hydrogen sulphide were studied. Growth studying ( $\mathrm{H}$-form) was performed by seeding $0.5 \mathrm{ml}$ of the investigated sample in a test tube with a nutrient media of MPA with TTC (tetrazolium red-2,3,5 tetraphenyl tetrazole chloride). Cultivated for 20 hours at $37^{\circ} \mathrm{C}$ (Stockert et al., 2018). On three-sugar agar with Mohr's salt showed the formation of the hydrogen sulphide, and on three-sugar agar with urea - splitting of the urea. From the typical colonies, preparations were made and studied morphology of cells, by microscopy. These colonies were reseed, studied their mobility, cultural and enzymatic properties. We carried out the examination of the material from suspicious colonies in the Krumvid-Olkennytsky media in the Kovalchuk modification, where the protease group's bacteria were painted in a bright red color (due to the splitting of urea) and formed a black precipitate with a rupture of the column of the media (due to the formation of hydrogen sulphide) (Thompson et al., 2018). In determining enterobacteria, ten times breeding was prepared and seeded $1 \mathrm{ml}$ in each of the three bacteriological cups filled with $10 \mathrm{ml}$ of purple-red bile glucose agar. From above, after freezing, we laid the same media and cultivated at $37^{\circ} \mathrm{C}$ for 24 hours. To confirm the results, five typical pink-purple colonies from cups to a non-selective media (MPA) for enterobacteria were carried out by conducting a test for glucose fermentation and formation of oxidase. Cultivated at $37{ }^{\circ} \mathrm{C}$ for 24 hours. The oxidase test was performed by applying to a filter paper, wetted with oxidase reagent, the bacterial mass. For a fermentation test for glucose, a colony with a negative reaction to oxidase, was transferred to glucose agar, again cultivated at the same mode (Vivijs et al., 2015). In a study on the presence of bacteria of the Salmonella genus, cultures were performed on the Rapaport-Vasiladis (RV), BairdParker (BP), and magnesium chloride media. Cultivated for 24 hours at a temperature of $37^{\circ} \mathrm{C}$ and reseeded into selenite cystine media and urea three-sugar agar, followed by cultivation in the same mode (Badr, 2004).

The finished preparations were stained according to Gram in common way (Pinnock et al., 2017).

\section{Preparing and study of histological sections of the intestine and liver}

The material for histological analysis was biopreparations of the liver and distal part of the small intestine. Samples were taken from 120-day-old rabbits, fed a "Bio-active" prebiotic at a dose of $2.0 \mathrm{~g}$ per animal for 30 days. Histological studies were conducted at the Laboratory of Path anatomy as part of the Department of Veterinary and Sanitary Expertise, Hygiene of Livestock Production, and Path anatomy named after Y.S. Zagayevsky (Bila Tserkva National Agrarian University). Tissue specimens were fixed with $10 \%$ neutral formalin solution, dehydrated in alcohols, sealed in colloid, and performed histological sections of 7-10 $\mu \mathrm{m}$ thickness on a microtome MC-2 (Russian Federation). Histology sections were stained with hematoxylin and eosin (Alturkistani et al., 2015). Histopathologic diagnostics were performed using a light optic trinocular microscope Axiostar plus (Carl Zeiss, Germany), a digital micro-attachment with a "Canon Power Shot Gb" adapter, which performed macro photography of the test material.

\section{Results and Discussion}

Probiotics and prebiotics are one of the modern ways of correcting the adaptive capacity of an organism of farm animals due to adverse medial factors.

\section{Influence at mass growth and preservation of rabbits}

At the first stage of our research, it was established that the prebiotic "Bio-active" contributed to the activation of the natural resistance, growth intensity and development of rabbits of the gray giant breed (Table 1).

The additional weight gain of each animal increased without additional costs of feed. So, for rabbit weight gain by $1 \mathrm{~kg}$, it was spent $14.3 \%$ less energy feed. This will significantly increase the profitability of rabbit meat production.

As a result of the 30 days application of the "Bio-active" prebiotic, it was found that during the 96-day retention period there were no disturbances in the function of the gastrointestinal tract of rabbits. Preservation in the control group was $60 \%$, as the animals died as a result of gastroenteritis. Consequently, the oral use of the "Bio-active" prebiotic during 30 days for young rabbits at a dose 
of $2.0 \mathrm{~g}$ per animal, which provided $95 \%$ animal preservation, is optimal. That is why all further researches were carried out on animals of this particular group (Experiment 4).

Table 1. Preservation and intensity of rabbit growth after using of "Bio-active" prebiotic during 30 days (M $\pm m$, average 96 days).

\begin{tabular}{lcccccc}
\hline Animal groups & $\begin{array}{c}\text { Number of } \\
\text { animals in the } \\
\text { group }\end{array}$ & Dose, g/animal & $\begin{array}{c}\text { Increase in the intensity of } \\
\text { mass growth }\end{array}$ & $\begin{array}{c}\text { Preservation, } \\
\%\end{array}$ & $\begin{array}{c}\text { Additional } \\
\text { mass gain, kg }\end{array}$ \\
\hline Experiment 1 & 20 & 0.8 & $22.0^{*}$ & 29.4 & 95.0 & 0.403 \\
Experiment 2 & 19 & 1.0 & $23.2^{*}$ & 35.3 & 80.0 & 0.518 \\
Experiment 3 & 18 & 1.5 & $22.3^{*}$ & 23.0 & 80.0 & 0.432 \\
Experiment 4 & 20 & 2.0 & $22.0 * *$ & 43.1 & 95.0 & 0.403 \\
Control & 16 & - & 17.2 & - & 60.0 & - \\
\hline
\end{tabular}

Note: Compared to the control group animals: $*-p<0,05 ; * *-p<0,01$

\section{Influence at microflora of the intestinal tract of rabbits}

Comparing the results of bacteriological research of scarifies of the rabbits' distal small intestinal tract, we conclude that prebiotic preparation had a positive effect on the intestinal microflora, confirming the previous results of our research (Table 2 ).

Table 2. Features of the microflora of the distal intestinal tract in rabbits after feeding with "Bio-active" prebiotic during 30 days (average 96 days), $\mathrm{n}=10$.

\begin{tabular}{lcc}
\hline Microorganisms & \multicolumn{2}{c}{ Animal groups } \\
\cline { 2 - 3 } & Experiment 4 & Control \\
\hline Total number of microorganisms, CFU & $10^{11}-10^{12}$ & $10^{8}-10^{9}$ \\
Coccus bacteria & $3 \times 10^{9}$ & $10^{6}-10^{7}$ \\
Bacteria of Proteus genus & found in $20 \%$ of animals & found in $100 \%$ of animals \\
The total number of E. coli group's bacteria, CFU & $2 \times 10^{8}$ & $4 \times 10^{8}$ \\
Haemolytic E. coli & not found & not found \\
Lactose-negative Enterobacteriaceae, CFU & $4,5-6,0 \times 10^{8}$ & $10^{5}-10^{6}$ \\
Bifidobacteria, CFU & $8 \times 107-10^{8}$ & $10^{6}-10^{7}$ \\
Pathogenic bacteria of intestinal infections & not found & not found \\
(Salmonella, Klebsiella) & not found & not found \\
Haemolytic Staphylococcus & not found & not found \\
Fungi of Candida genus & & \\
\hline
\end{tabular}

It can be explained the effect of prebiotic "Bio-active" on the natural resistance of animals, based on the positions that it consists of biologically active substances produced by lactobacilli. Under normal conditions, living bacteria from the representatives of the normal microflora of the intestinal biocenosis populate the intestine with competing strains of probiotic bacteria, which carry out non-specific control of the conditionally pathogenic microflora by displacing it from the intestinal population of microorganisms and inhibiting the development of its pathogenicity (Bhatt et al.; Satish et al., 2017).

The antagonism of pro- and prebiotics in relation to action on pathogenic microflora is due to the production of organic protein peptides. Probionate bacteria represent a kind of "reactor" with the formation of enzymes in it, amino acids, vitamins and bacteriocin, which neutralize pathogenic microorganisms (Lauková et al. 2016; Sharma et al., 2016).

As the results of our studies have shown, precisely because of the processes described, the scaricas of the intestinal mucosa of rabbits after using of prebiotics were not detected haemolytic strain of E. coli (Goldwater and Bettelheim, 2012), Salmonella (Zihler et al., 2011), Klebsiella (Ly et al., 2011), haemolytic Staphylococcus (Sikorska and Smoragiewicz, 2013), and fungi of Candida genus (Matsubara et al., 2016).

In addition to the presence and quantity of microorganisms in scarifies of rabbits' distal intestinal tract, from our point of view, it was important to determine the ratio of gram-positive and gram-negative microorganisms. It is known, that decrease in the grampositive/gram-negative ratio occurs when the inflammatory of the intestine is enhanced, because of gram-negative bacteria produce lipopolysaccharides, some of which are potential endotoxins (Lankelma et al., 2017). The results of this calculation are presented in Figure 1. As can be seen, the gram-positive/gram-negative ratio in rabbits that did not receive the prebiotic preparation was 1 : 2.9 , while in animals from the Experiment 4 group, this indicator was 1: 1.17. It is indicating a general improvement in the functioning of the digestive tract, which, in turn, leads to an improvement in the absorption of nutrients in the feed and to an increase in weight gain.

\section{Influence at histological structure of the intestine and liver}

The histological study of the wall of the distal small intestine, as well as the liver, allowed expanding the data on the influence of "Bio-active" prebiotic on the structure of organs responsible for digestion and assimilation of feed.

In the mucous membrane of the small intestines of the Experiment 4 group rabbits, its' structure was clearly visible. Crypts, located closer to the basement membrane, contained a significant amount of secretion (Figure 2).

In most crypts, numerous goblet cells have been identified, indicating increased secretion. The other part of the crypts contained a moderate amount of oxyphilic pale pink secretion. Intestinal vessels (various calibres) were dilated and filled with blood. In control group, the decreased secretion of the epithelial layer of the small intestine was detected. Structural changes in the test material indicate that the products of metabolism of lactic acid bacteria Lactobacillus bulgaricus delbrueckii, which are active substances in prebiotic "Bio-active", stimulates secretion in the small intestine, improves digestion and absorption of feed (Bellmann et al., 2015; Cheng, 2016). After each feeding of animals, a number of pathogenic bacteria inevitably enter the digestive channel. As known, the intestinal mucosa is a continuous secreted and cellular surface barrier for potential intestinal pathogens. Goblet cells secrete large amounts of mucin glycoproteins, and specialized Paneth cells produce antimicrobial molecules. Together they form a mucous barrier for infectious agents (McGuckin et al, 2011; Sassone-Corsi and Raffatellu, 2015). 


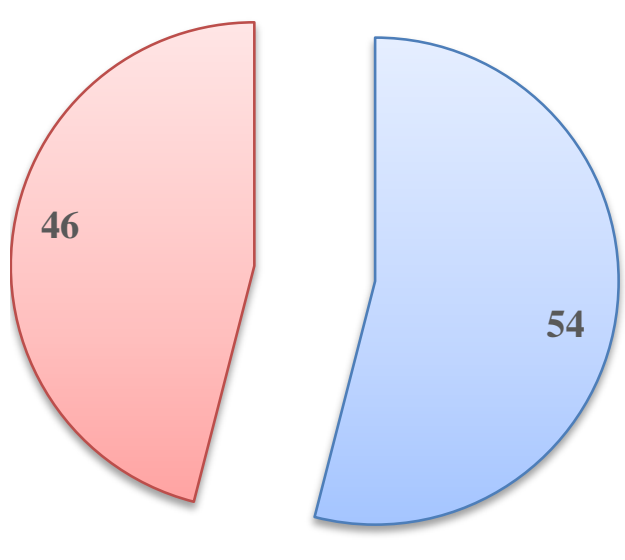

$\square$ Gram-positive

$\square$ Gram-negative

a
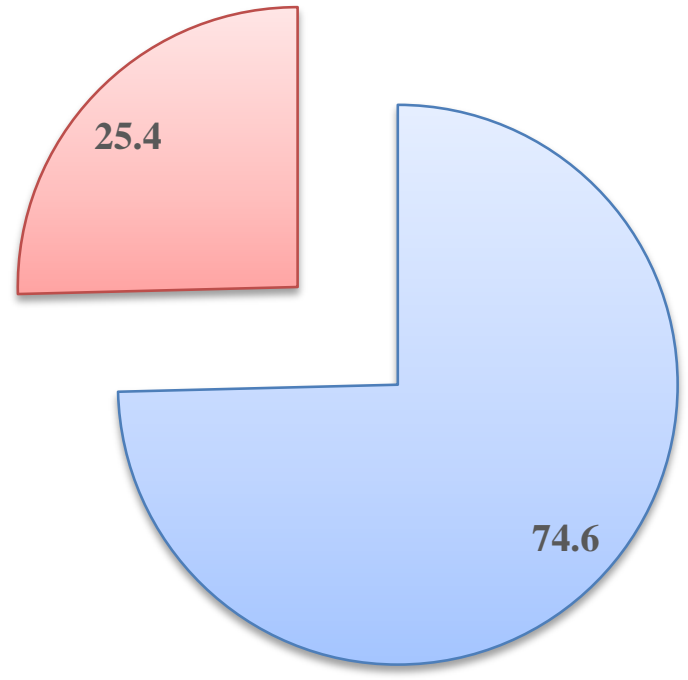

b

Fig. 1. Ratio of microflora in scarifies of rabbits' distal intestinal tract: a - after feeding with "Bio-active" prebiotic during 30 days (Experiment 4 group); b - control group.

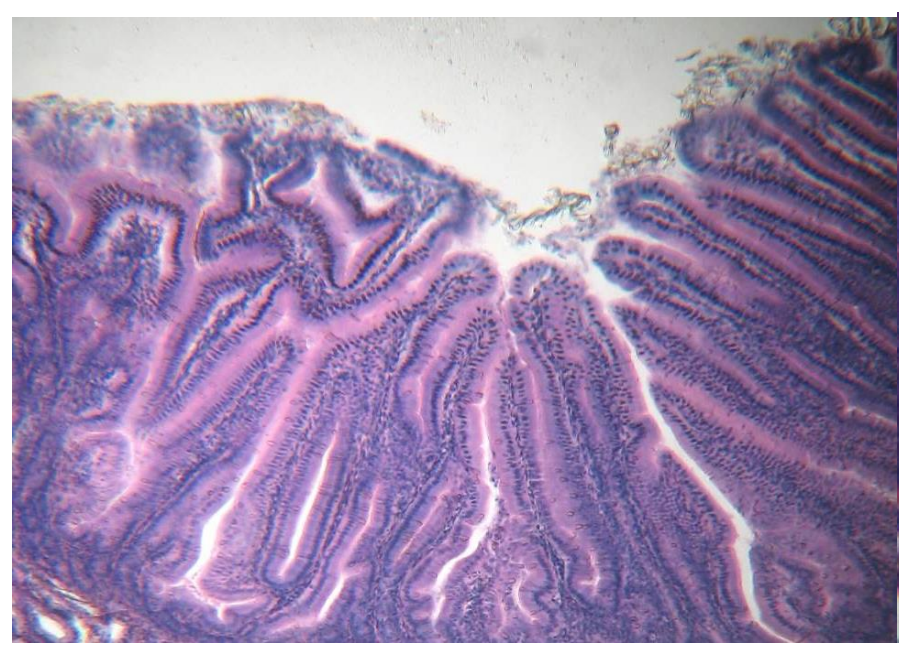

a

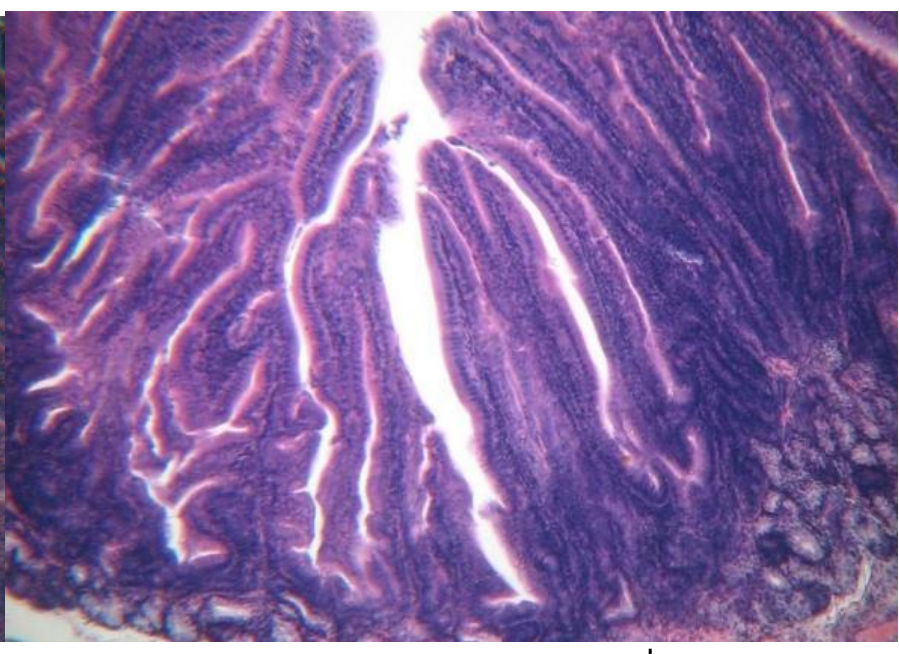

b

Fig. 2. The structure of the rabbit's small intestine distal part: a - after feeding with "Bio-active" prebiotic during 30 days (Experiment 4 group); b - control group. Stained with hematoxylin and eosin. Increment $\times 100$.

As shown by the results of our research, the products of the metabolism of lactobacilli, provided they are continuously fed for a long time, can stimulate the formation of bigger number of goblet cells per unit area of the mucous membrane in rabbits. As a result, the second effect is manifested - enhanced protection of the intestinal wall against the penetration of pathogenic microbes and the suppression of their reproduction. The chain character of this process develops, and is manifested by a decrease in the influence of toxins secreted by the pathogenic microflora. The principle is very simple: fewer microorganisms - less toxins produced by them in the process of metabolism. The final result of this chain reaction is an improvement in the state of the organs that are responsible for neutralizing toxic substances, in the first place - the liver.

Studied the liver histological structure in the Experiment 4 group rabbits, we found that only $25 \%$ of the animals had fatty hepatodystrophy, and $15 \%$ had protein granular dystrophy (Figure 3). It is suggests that absorption of the feed nutrients was high levelled in this group (Tahara and Shibata, 2016). A moderate amount of fatty acids was absorbed from the gastrointestinal tract, normal lipolysis was observed in hepatocytes, and the accumulation of neutral fats in liver cells was negligible. Such a process is dynamic and conditionally physiological, and therefore does not indicate a possible threat to the general health of the animal (Saponaro et al. 2015; Mayada et al., 2015). In the liver of animals in the control group, significantly more threatening indicators were observed: in $74.5 \%$ of the test material, there was fatty hepatodistrophy and in $25.5 \%$ was protein granular dystrophy. Thus, the liver of all animals was affected by dystrophic changes. This phenomenon can be explained, first, by reduced secretion of the glands of the intestinal mucosa. As a result, the synthesis of otoproteins increased, which, in turn, intensified the absorption and excessive intake of fatty acids. With increased lipolysis, hepatocytes accumulated neutral fats (Martinez-Lopez et al., 2016). The results obtained by us give grounds to speak about the positive effects of prebiotics, which contributes to the reduction of degenerative processes in the liver. 


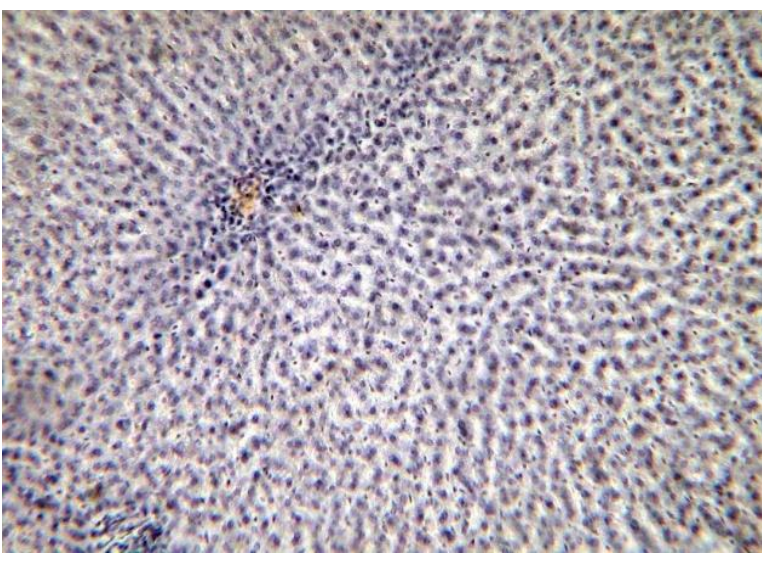

a

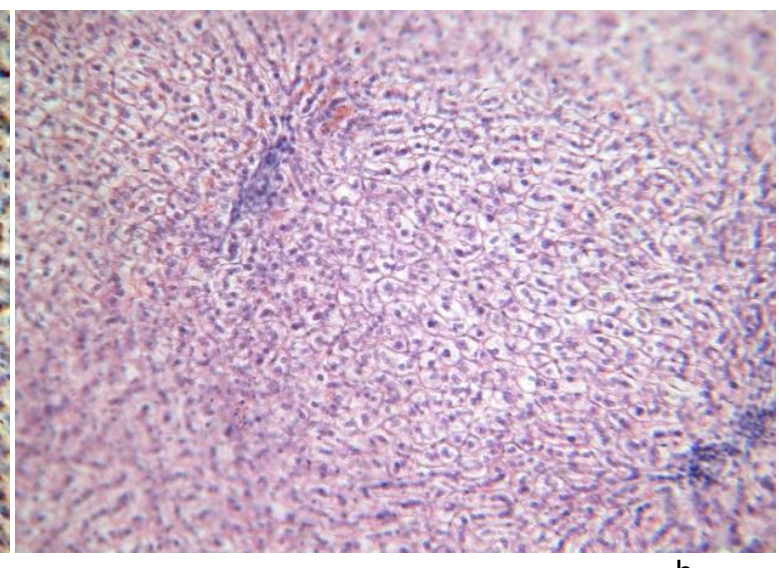

b

Fig. 3. Fragment of the rabbit's liver structure: a - after feeding with "Bio-active" prebiotic during 30 days (Experiment 4 group); b control group (protein granular hepatocyte dystrophy). Stained with hematoxylin and eosin. Increment $\times 200$.

\section{Conclusion}

The most effective scheme for oral administration of "Bio-active" prebiotic for young rabbits was its feeding for 30 days at a dose of $2.0 \mathrm{~g}$ per $1 \mathrm{~kg}$ of body weight. Such a course provided $95 \%$ of animal preservation, so it was identified as optimal. After this course, we also observed an increase in the weight gain of the experimental animals, which was an average of $43.1 \%(+0.403 \mathrm{~kg})$ on the 96th day of the experiment compared with the non-treated rabbits. That is mean that the preparation contributed to activating the energy and plastic needs of experimental animals' organism and formed the main metabolic pathways for its functioning.

Positive effect of "Bio-active" prebiotic at the development of normal microflora and inhibition of reproduction of pathogenic microorganisms in the intestines of rabbits has been established. Bacteria of Proteus genus have been detected in scarifies of rabbits' distal intestinal tract in $20 \%$ of animals that have passed the optimal course of prebiotic use and in $100 \%$ of those who did not receive the preparation. After the course of prebiotic in the intestines of rabbits showed an increased number of lactosenegative Enterobacteriaceae (4.5-6.0×108 CFU) and Bifidobacteria ( $8 \times 107-108 \mathrm{CFU})$. At the same time, in the control group rabbits, these indices were 105-106 and 106-107 CFU respectively.

Under the influence of lactic acid bacteria Lactobacillus bulgaricus delbrueckii metabolism's products, which are active substances of prebiotic "Bio-active", has improved the gram-positive / gram-negative ratio with a predominance of gram-positive (1: 1.17 against 1: 2.9 in rabbits of control group), which is a physiologically characteristic phenomenon for the distal intestinal tract, and helps to ensure the normal processes of assimilation and dissimilation of the digestive mass.

In the case of prebiotic preparation using, by histological examination of the small intestine walls, stimulation of goblet cells' development has been established which results in increased secretion of the mucous membrane. This leads to an improvement in the absorption of nutrients from the feed, as well as to the inhibition of the pathogenic intestinal microflora development. One of the consequences of this effect was found during the liver histological examination $-100 \%$ of rabbits who did not receive prebiotic, had signs of dystrophic changes in hepatocytes (fatty hepatodistrophy in $74.5 \%$ and protein in $25.5 \%$ ), while the animals that received the optimal course of the preparation, these indicators were significantly lower ( 25 and $15 \%$ respectively).

\section{References}

Alturkistani, H.A., Tashkandi, F.M., \& Mohammedsaleh, Z.M. (2015). Histological Stains: A Literature Review and Case Study. Global journal of health science, 8(3), 72-79. https://doi.org/10.5539/gjhs.v8n3p72

Arrazuria, R., Elguezabal, N., Juste, R.A., Derakhshani, H., \& Khafipour, E. (2016). Mycobacterium avium Subspecies paratuberculosis Infection Modifies Gut Microbiota under Different Dietary Conditions in a Rabbit Model. Front. Microbiol, 7 , 446. https://doi.org/10.3389/fmicb.2016.00446

Badr, H.M. (2004). Use of irradiation to control foodborne pathogens and extend the refrigerated market life of rabbit meat. Meat Science, 67(4), 541-548. https://doi.org/10.1016/j.meatsci.2003.11.018.

Bellmann, S., Carlander, D., Fasano, A., Momcilovic, D., Scimeca, J.A., Waldman, W.J., Gombau, L., Tsytsikova, L., Canady, R., Pereira, D.I.A., \& Lefebvre, D.E. (2015). Mammalian gastrointestinal tract parameters modulating the integrity, surface properties, and absorption of food-relevant nanomaterials. WIREs Nanomedicine and Nanobiotechnology, 7(5), 609-622. https://doi.org/10.1002/wnan.1333

Beyene, T. (2016). Veterinary Drug Residues in Food-animal Products: Its Risk Factors and Potential Effects on Public Health. J Veterinar Sci Technol, 7(1), 285-291. http://dx.doi.org/10.4172/2157-7579.1000285

Bhatt, R.S., Agrawal, A.R., \& Sahoo, A. (2017). Effect of probiotic supplementation on growth performance, nutrient utilization and carcass characteristics of growing Chinchilla rabbits. Journal of Applied Animal Research, 45(1), 304-309. https://doi.org/10.1080/09712119.2016.1174126

Blaser, M.J. (2016). Antibiotic use and its consequences for the normal microbiome. Science, 352(6285), 544-545. https://doi.org/10.1126/science.aad9358

Cheng, H.M. (2016) Secretion of Digestive Juices. In: Cheng H. (eds) Physiology Question-Based Learning. Springer, Singapore. https://doi.org/10.1007/978-981-10-0877-1_11

Donaldson, G.P., Lee, S.M., \& Mazmanian, S.K. (2016). Gut biogeography of the bacterial microbiota. Nature Reviews Microbiology, 14, 2032. https://doi.org/10.1038/nrmicro3552

Ford, A.C., Harris, L.A., Lacy, B.E., Quigley, E.M.M., Moayyedi, P. (2018). Systematic review with meta-analysis: the efficacy of prebiotics, probiotics, synbiotics and antibiotics in irritable bowel syndrome. Alimentary Pharmacology and Therapeutics, 48(10), 1044-1060. https://doi.org/10.1111/apt.15001

Geetanjali Sharma, K., Vidyarthi, V.K., Archana, K., \& Zuyie, R. (2016). Probiotic Supplementation in the Diet of Rabbits - A Review. Livestock Research International, 4(1), 01-10.

Goldwater, P.N., \& Bettelheim, K.A. (2012). Treatment of enterohemorrhagic Escherichia coli (EHEC) infection and hemolytic uremic syndrome (HUS). BMC Medicine, 10, 12-19. https://doi.org/10.1186/1741-7015-10-12 
Lankelma, J.M., van Vught, L.A., Belzer, C., Schultz, M.J., van der Poll, T., de Vos, W.M., \& Wiersinga, W.J. (2017). Critically ill patients demonstrate large interpersonal variation in intestinal microbiota dysregulation: a pilot study. Intensive Care Med, 43, 59-68. https://doi.org/10.1007/s00134-016-4613-z

Lauková, A., Simonová, M.P., Chrastinová, L., Plachá, I., Čobanová, K., Formelová, Z., Chrenková, M., Ondruška, L., \& Strompfová, V. (2016). Benefits of combinative application of probiotic, enterocin M-producing strain Enterococcus faeciumAL41 and Eleutherococcus senticosus in rabbits. Folia Microbiol, 61(2), 169-177. https://doi.org/10.1007/s12223-015-0423-x

Ly, N.P., Litonjua, A., Gold, D.R., \& Celedón, J.C. (2011). Gut microbiota, probiotics, and vitamin D: Interrelated exposures influencing allergy, asthma, and obesity? Journal of Allergy and Clinical Immunology, 127(5), 1087-1094. https://doi.org/10.1016/j.jaci.2011.02.015

Martinez-Lopez, N., Garcia-Macia, M., Sahu, S., Athonvarangkul, D., Liebling, E., Merlo, P., Cecconi, F., Schwartz, G.J., \& Singh, R. (2016). Autophagy in the CNS and Periphery Coordinate Lipophagy and Lipolysis in the Brown Adipose Tissue and Liver. Cell Metabolism, 23(1), 113-127. https://doi.org/10.1016/j.cmet.2015.10.008

Matsubara, V.H., Bandara, H.M.H.N., Mayer, M.P.A., \& Samaranayake, L.P. (2016). Probiotics as Antifungals in Mucosal Candidia sis. Clinical Infectious Diseases, 62(9), 1143-1153. https://doi.org/10.1093/cid/ciw038

Mayada, R.F., Taghred, M.S., \& Haytham, A.A. (2015). Boldenone-induced apoptotic, structural, and functional alterations in the liver of rabbits. World Rabbit Science, 23(1), 39-46. https://doi.org/10.4995/wrs.2015.2261.

McGuckin, M.A., Lindén, S.K., Sutton, P., \& Florin, T.H. (2011). Mucin dynamics and enteric pathogens. Nature Reviews Microbiology, 9 , 265-278. https://doi.org/10.1038/nrmicro2538

Phuoc, T.L., \& Jamikorn, U. (2016). Effects of probiotic supplement (Bacillus subtilis and Lactobacillus acidophilus) on feed efficiency, growth performance, and microbial population of weaning rabbits. Asian-Australasian journal of animal sciences. 30(2), 198-205. https://doi.org/10.5713/ajas.15.0823

Pinnock, A., Shivshetty, N., Roy, S., Rimmer, S., Douglas, I., MacNeil, S., \& Garg, P. (2017). Ex vivo rabbit and human corneas as models for bacterial and fungal keratitis. Graefes Arch Clin Exp Ophthalmol. 255(2), 333-342. https://doi.org/10.1007/s00417-016-3546-0

Rios, D., Wood, M.B., Li, J., Chassaing, B., Gewirtz, A.T., \& Williams, I.R. (2016). Antigen sampling by intestinal M cells is the principal pathway initiating mucosal IgA production to commensal enteric bacteria. Mucosal Immunology. 9, 907-916. https://doi.org/10.1038/mi.2015.121

Saponaro, C., Gaggini, M., Carli, F., \& Gastaldelli, A. (2015). The Subtle Balance between Lipolysis and Lipogenesis: A Critical Point in Metabolic Homeostasis. Nutrients, $\pi 11)$, 9453-9474. https://doi.org/10.3390/nu7115475

Sassone-Corsi, M., \& Raffatellu, M. (2015). No Vacancy: How Beneficial Microbes Cooperate with Immunity To Provide Colonization Resistance to Pathogens. The Journal of Immunology, 194(9), 4081-4087. https://doi.org/10.4049/jimmunol.1403169

Satish, L., Gallo, P.H., Johnson, S., Yates, C.C., \& Kathju, S. (2017). Local Probiotic Therapy with Lactobacillus plantarum Mitigates Scar Formation in Rabbits after Burn Injury and Infection. Surgical Infections, 18(2), 119-127. https://doi.org/10.1089/sur.2016.090

Sikorska, H., \& Smoragiewicz, W. (2013). Role of probiotics in the prevention and treatment of meticillin-resistant Staphylococcus aureus infections. International Journal of Antimicrobial Agents, 42(6), 475-481. https://doi.org/10.1016/j.ijantimicag.2013.08.003

Stockert, J.C., Horobin, R.W., Colombo, L.L., \& Blázquez-Castro, A. (2018). Tetrazolium salts and formazan products in Cell Biology: Viability assessment, fluorescence imaging, and labeling perspectives. Acta histochemical, 120(3), 159-167. https://doi.org/10.1016/j.acthis.2018.02.005

Tahara, Y., \& Shibata, S. (2016). Circadian rhythms of liver physiology and disease: experimental and clinical evidence. Nature Reviews Gastroenterology \& Hepatology, 13, 217-226. https://doi.org/10.1038/nrgastro.2016.8

Thompson, R., Perry, J.D., Stanforth, S.P., \& Dean, J.R. (2018). Rapid detection of hydrogen sulfide produced by pathogenic bacteria in focused growth media using SHS-MCC-GC-IMS. Microchemical Journal, 140, 232-240. https://doi.org/10.1016/j.microc.2018.04.026

Tsuboi, K., Nishitani, M., Takakura, A., Imai, Y., Komatsu, M., \& Kawashima, H. (2015). Autophagy Protects against Colitis by the Maintenance of Normal Gut Microflora and Secretion of Mucus. The Journal of Biological Chemistry, 290, 20511-20526.

Vivijs, B., Haberbeck, L.U., Baiye Mfortaw Mbong, V., Bernaerts, K., Geeraerd, A.H., Aertsen, A., \& Michiels, C.W. (2015). Formate hydrogen lyase mediates stationary-phase deacidification and increases survival during sugar fermentation in acetoin-producing enterobacteria. Front. Microbiol, 6, 150. https://doi.org/10.3389/fmicb.2015.00150

Wiley, N.C., Dinan, T.G., Ross, R.P., Stanton, C., Clarke, G., \& Cryan, J.F. (2017). The microbiota-gut-brain axis as a key regulator of neural function and the stress response: Implications for human and animal health. Journal of Animal Science, 95(7), 3225-3246. https://doi.org/10.2527/jas.2016.1256

Yang, F., Wang, A., Zeng, X., Hou, C., Liu, H., \& Qiao, S. (2015). Lactobacillus reuteri 15007 modulates tight junction protein expression in IPEC-J2 cells with LPS stimulation and in newborn piglets under normal conditions. BMC Microbiology, 15, 32-42. https://doi.org/10.1186/s12866-015-0372-1

Zantow, J., Moreira, G.M.S.G., Dübel, S., \& Hust, M. (2018). ORFeome Phage Display. In: Hust M., Lim T. (eds) Phage Display. Methods in Molecular Biology, 1701. Humana Press, New York, NY. https://doi.org/10.1007/978-1-4939-7447-4_27

Zhang, Y., Hong P.-Y., LeChevallier, M.W., \& Liu, W.-T. (2015). Phenotypic and Phylogenetic Identification of Coliform Bacteria Obtained Using 12 Coliform Methods Approved by the U.S. Mediaal Protection Agency. Appl. Environ. Microbiol, 81(17), 6012-6023. https://doi.org/10.1128/AEM.01510-15

Zihler, A., Gagnon, M., Chassard, C., \& Lacroix, C. (2011). Protective effect of probiotics on Salmonella infectivity assessed with combined in vitro gut fermentation-cellular models. BMC Microbiology, 11, 264-276. https://doi.org/10.1186/1471-2180-11-264

\section{Citation:}

Lyasota, V.P., Bakhur, T.I., Utechenko, M.V., Fedorchenko, M.M., Rublenko, I.O., Bukalova, N.V., Bogatko, N.M., Antipov, A.A., Tkachuk, S.A., Prilipko, N.I., Sakhniuk, T.M., Bogatko, A.F. (2020). Effect of a complex prebiotic preparation on the preservation, growth intensity and microflora in rabbits' intestine. Ukrainian Journal of Ecology, 106), 6-11.

(cc) EY This work is licensed under a Creative Commons Attribution 4.0. License 